\title{
A safer technique for the double elevation osteotomy in severe infantile tibia vara
}

\author{
Hany Hefny $\cdot$ Hisham Shalaby
}

Received: 19 February 2009/ Accepted: 26 April 2010/Published online: 20 May 2010

(C) The Author(s) 2010. This article is published with open access at Springerlink.com

\begin{abstract}
Infantile tibia vara is a deformity of abrupt angulation into varus due to an affection of the postromedial aspect of the proximal tibial physis. The deformity often includes internal tibial torsion and limb length discrepancy. Gradual correction of the deformity is currently the treatment of choice for these challenging cases as it requires less invasive surgery, allows progressive and adjustable correction, permits bone lengthening if needed and achieves a more accurate correction compared to acute correction. Elevation of the depressed medial tibial condyle allows restoration of the joint architecture. Different techniques described to elevate the depressed medial tibial plateau are all technically demanding and carry potential risks of unsalvageable intra-operative complications. The aim of this study is to report the results of a safer technique for the double elevation osteotomy combined with gradual correction using the Ilizarov frame, allowing it to be more reproducible, less technically demanding and avoid those potential complications. This study included 12 limbs in 8 patients (mean age 9 years), all were classified as stage $\mathrm{V}$ or VI according to the Langenskiold classification. All osteotomies healed completely in all patients. The mean time in the frame was 23 weeks. The mean preoperative
\end{abstract}

\section{H. Hefny}

Orthopedic Department, Demerdash Hospital,

Ain Shams University, Abbasseia Square, Cairo, Egypt

e-mail: hanyhefny@yahoo.com

H. Shalaby $(\bowtie)$

Orthopedic Department, Ain Shams University,

3B Foad Basha St., Mansheiat El-Bakry,

Heliopolis, Cairo, Egypt

e-mail: hishamshalaby@yahoo.com femoral shaft-tibial shaft angle was $36^{\circ}$ of varus. This improved to $5^{\circ}$ of varus. The mean preoperative femoral condyle-tibial shaft angle was $58^{\circ}$. This improved to $84^{\circ}$. The mean preoperative angle of depressed medial tibial plateau was $63^{\circ}$. This improved to $8^{\circ}$. All patients were maintaining full extension of the knee at the final follow-up, and all patients noticed a significant improvement in their gait pattern. We believe that this technique is safer and less invasive compared to traditional and even newly described techniques for elevating the depressed medial tibial plateau and correcting the deformity in severe infantile tibia vara, which will allow it to be more reproducible.

Keywords Tibia vara - Blount's disease .

Double elevation osteotomy · Ilizarov · Gradual correction

\section{Introduction}

Tibia vara is a deformity of abrupt angulation into varus below the knee and inward rotation of the tibia [1-3]. Several factors have been blamed for the aetiology of the condition including genetic [4], dysplastic [5], traumatic and mechanical theories [6-8], all of which implying an ultimate affection of the postromedial aspect of the proximal tibial physis.

Among different forms described in the literature, infantile tibia vara, which manifests itself between the ages of 1 and 4 years, is the most challenging entity [9].

Gradual correction of the deformity is currently the treatment of choice for these challenging cases as it requires less invasive surgery, allows progressive and adjustable correction, permits bone lengthening if needed and achieves a more accurate correction compared to acute correction [10-16]. 
Elevation of the depressed medial tibial condyle has been described for the management of advanced stages of Infantile tibia vara to restore the joint architecture [17-20]. The authors described the elevation of the depressed medial tibial plateau in patients with severe neglected infantile tibia vara using a double elevating tibial osteotomy in conjunction with the Ilizarov technique [21].

These different techniques described to elevate the depressed medial tibial plateau are all technically demanding and carry potential risks of unsalvageable intraoperative complications as intra-articular fractures.

The aim of this study is to report the results of a modification to the operative technique of the double elevating tibial osteotomy [21], in an attempt to achieve a more reproducible and less technically demanding approach to these challenging cases.

\section{Patients and methods}

This study included 12 limbs in 8 patients (5 males and 3 females), with severe infantile tibia vara. The mean age at the time of the operation was 9 years (ranging from 7 to 12 years). All patients were troubled by the cosmetic appearance of the severe deformity but were also complaining of awkward gait and discomfort in the knee region after prolonged walking and vigorous activities.

Two patients (2 limbs) had previous corrective osteotomies fixed with plate and screws. For these two patients, the osteotomies have healed completely but the deformity recurred again. In both patients, the previous osteotomy was performed below the level of the tibial tuberosity. The remaining patients had no previous conservative or surgical treatment.

Three patients (5 limbs) were grossly over weight with a body mass index (BMI) of more than 25 . All patients had a full range of movement in the knee and were walking with a considerable lateral thrust, in particular those with a BMI of more than 25 .

The 4 patients with unilateral deformities were assessed for limb length discrepancy clinically with wooden blocks under the deformed side, and this showed a mean shortening on this side of $3 \mathrm{~cm}$ (ranging from 1.5 to $6 \mathrm{~cm})$.

Radiological assessment was done using long-leg standing hip-knee-ankle (HKA) X-rays with the patella pointing forward and the leg-length discrepancy corrected by wooden blocks under the short side.

We measured: (a) the angle formed by the anatomical axis of the femoral and tibial shafts (tibiofemoral angle), This angle is normally about $5^{\circ}$ of valgus, (b) the angle formed by the femoral condyle and the tibial shaft determined by a line drawn parallel to the inferior surface of the femoral condyle intersecting the anatomical axis of the tibia (femoral condyle-tibial shaft angle), this angle is normally about $90^{\circ}$, and (c) the angle of depression of the medial tibial plateau formed by a line drawn parallel to the proximal margin of the medial plateau intersecting a line drawn parallel to the lateral tibial plateau (angle of depressed medial tibial plateau). These radiological measurements have been used in several previous studies on tibia vara $[2,18,19]$ and by the authors in their previous series [21], (Fig. 1).

All patients included in this study were stage V or VI according to the Langenskiold classification [2]. The mean follow-up was 5 years (ranging from 3 to 7 years).

The technique of the double elevation osteotomy

The idea behind the double elevation osteotomy technique is to use one osteotomy to elevate the depressed medial plateau and another osteotomy to correct the rest of the deformity [21]. Both osteotomies are performed at the same setting.

The proximal osteotomy is an oblique curved osteotomy directed towards the intercondylar eminence without crossing the physis, performed using a sharp curved osteotome. The distal osteotomy is a transverse metaphyseal osteotomy performed perpendicular to the mechanical axis of the tibia just distal to the tibial tuberosity. A fibular osteotomy is performed in all patients at the junction of the proximal and middle thirds of the fibula.

The proximal osteotomy is distracted gradually to elevate the depressed medial plateau, while the distal osteotomy is distracted to correct the limb length discrepancy. The site of the hinges is then changed to a more distal location to allow correction of the rest of the deformity through the distal osteotomy.
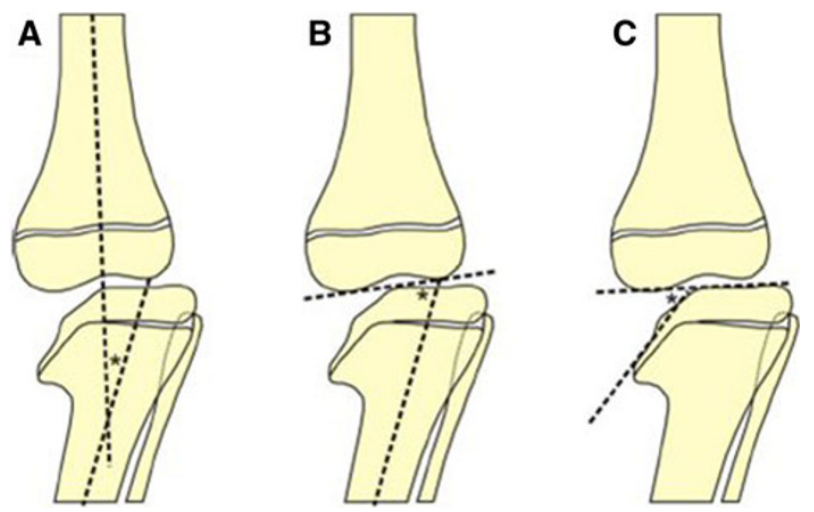

Fig. 1 Diagrammatic representation of the measurements used for preoperative planning, a Tibio-femoral angle, b Femoral condyletibial shaft angle and $\mathbf{c}$ Angle of depressed medial tibial plateau 
Fig. 2 Image intensifier picture showing the guide wire passed in an antro-posterior direction

Fig. 3 Diagrammatic representation of the process of tunnel drilling as seen in a lateral view image intensifier picture during the operation
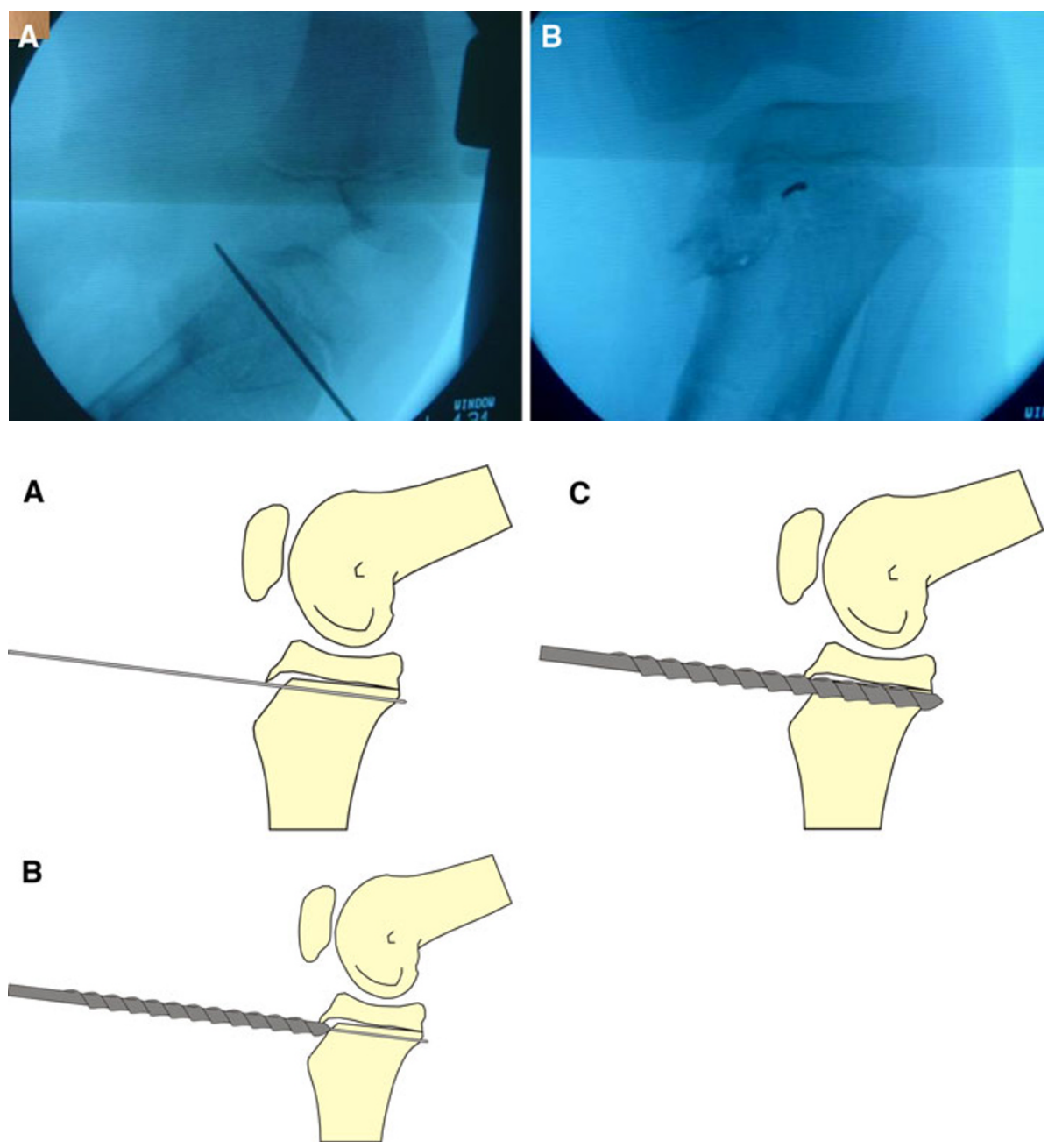

The modified technique of the double elevation osteotomy

A guide wire is inserted in an antro-posterior direction through a stab incision at the point intended to be the apex of the proximal osteotomy. This point should be at the level of the intercondylar eminence and the physis. This wire is initially introduced only to the posterior tibial cortex.

The limb is then positioned in external rotation with the knee in $90^{\circ}$ of flexion. A medial approach about $4 \mathrm{~cm}$ in length is then performed, and strict subperiosteal dissection is performed in a posterior direction to expose the site where the guide wire will penetrate the posterior tibial cortex. Under direct vision, the guide wire is introduced another $1 \mathrm{~cm}$ to protrude through the posterior cortex. All steps are performed under image intensifier guidance (Fig. 2).

An 8-mm cannulated drill bit is then introduced over the guide wire drilling from anterior to posterior. Care should be taken to keep the guide wire, which is protruding through the posterior cortex, under constant direct vision to

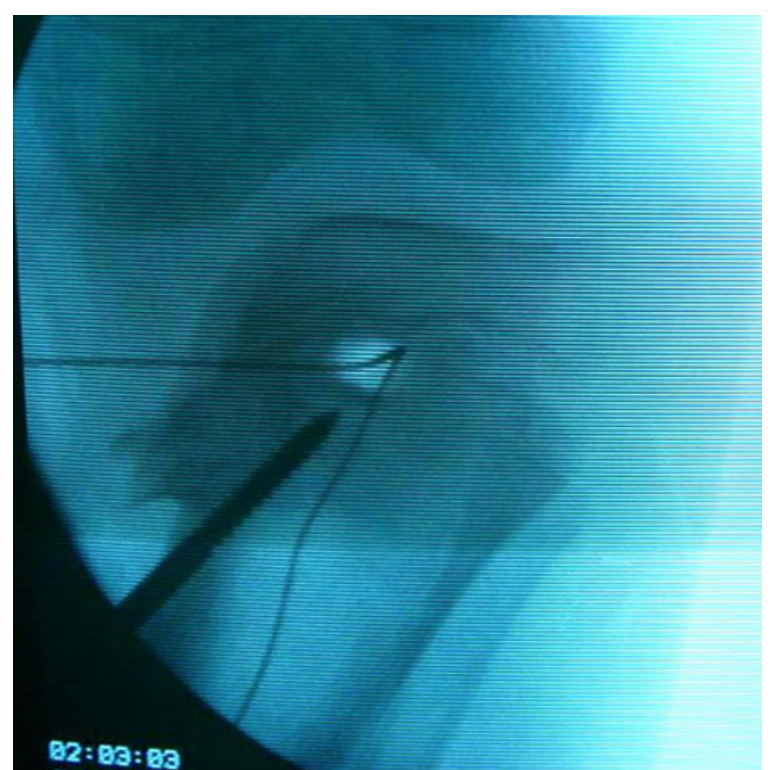

Fig. 4 Image Intensifier picture showing the Gigli saw passed through the tunnel created by the cannulated drill bit 
avoid its advancement during drilling. Should this happen the guide wire should be stabilized with a heavy forceps (Fig. 3).

A Gigli saw is then introduced through the tunnel created from an anterior to posterior direction and is picked up through the medial approach. Under image intensifier guidance, 2-3 half pins (5 $\mathrm{mm}$ in diameter) are inserted in the epiphyseal segment stopping at the intercondylar eminence (Fig. 4). The proximal osteotomy is then performed by oscillating the 2 limbs of the Gigli saw while pulling distally to create a medial proximal fragment fixed by the previously introduced half pins and hinging on the epiphysis.

A more distal transverse metaphyseal osteotomy perpendicular to the anatomical axis of the tibia is then performed. The fibula is osteotomised, and the half pins are connected to an appropriate Ilizarov ring. A distal base frame is applied to the tibia and connected to the proximal ring with a medial side motor (Fig. 5).
Postoperatively distraction is carried out medially at a rate of $1 \mathrm{~mm}$ a day. The initial placement of the hinges, corresponding to the intercondylar eminence, allows distraction to occur first through the proximal osteotomy, to elevate the depressed medial tibial plateau and correct part of the overall deformity. The distal osteotomy is simultaneously distracted at a slower rate of $0.25-0.5 \mathrm{~mm} / \mathrm{day}$, at the junction of the connecting rods to the proximal ring of the base frame, to prevent its premature fusion and to correct any concomitant limb length discrepancy. After sufficient elevation of the medial joint surface, the site of the hinges is changed to a more distal position. This is usually proximal and lateral to the distal osteotomy, which allows correction of the remaining varus deformity together with lateral translation to align the mechanical axis of the whole limb.

The frame is removed after complete healing of the two osteotomy sites as evident on follow-up X-rays. Patients are permitted weight bearing up to their tolerance postoperatively with no restriction on their daily activities.
Fig. 5 Diagrammatic representation of the double elevation osteotomy. a 1: antroposterior tunnel, 2: half pin inserted in the proximal fragment stopping just before the intercondylar eminence, 3: the direction of pull of the Gigli saw, 4: distal osteotomy perpendicular to the tibial shaft anatomical axis. b A two-ring construct assembled, the arrow shows the medial distraction. c After full correction 1: first position of the hinges to achieve correction through the proximal osteotomy, 2: second position of the hinges to achieve correction through the distal osteotomy. Note that this position allows correction of the varus deformity together with lateral translation to align the mechanical axis of the limb
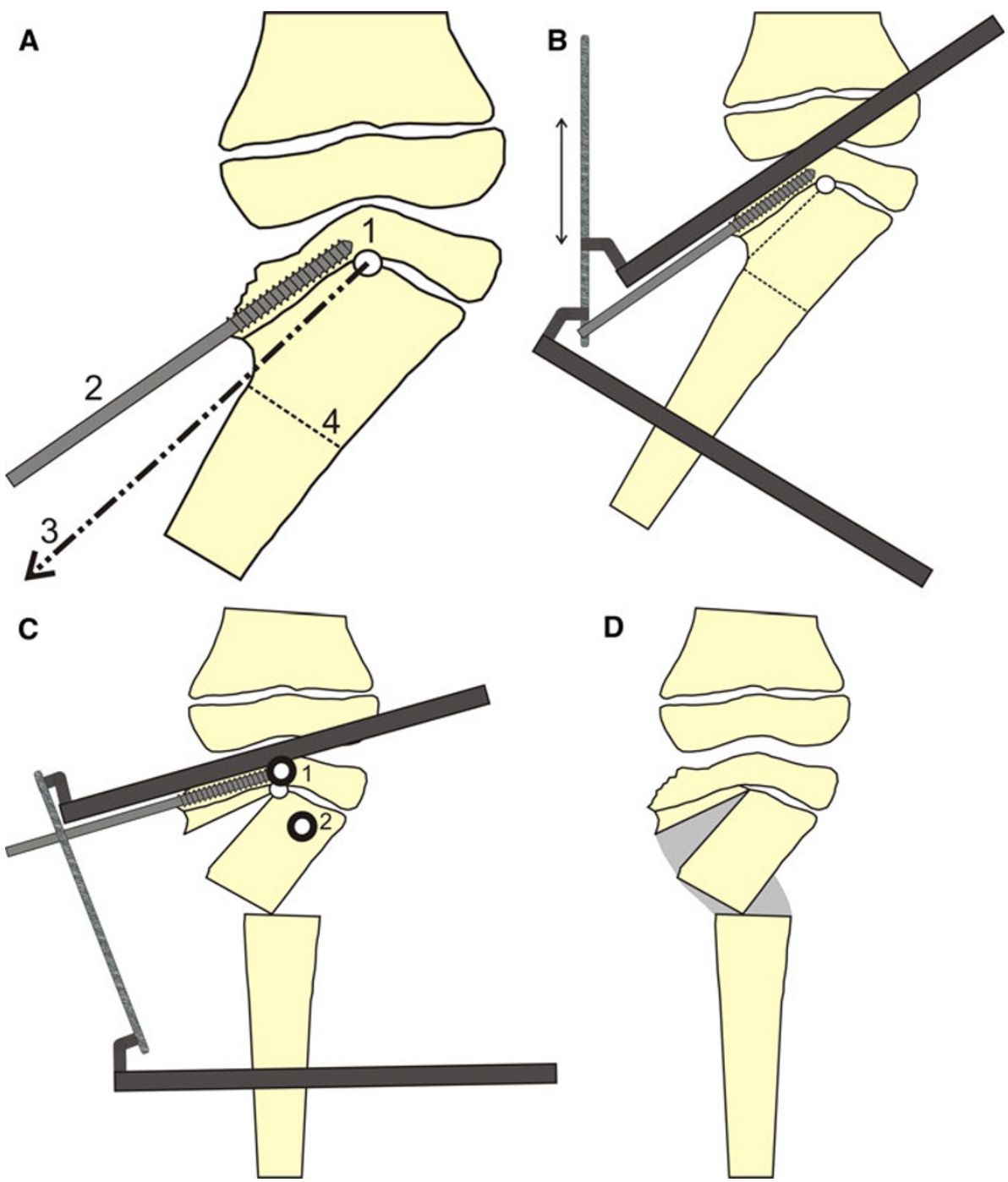

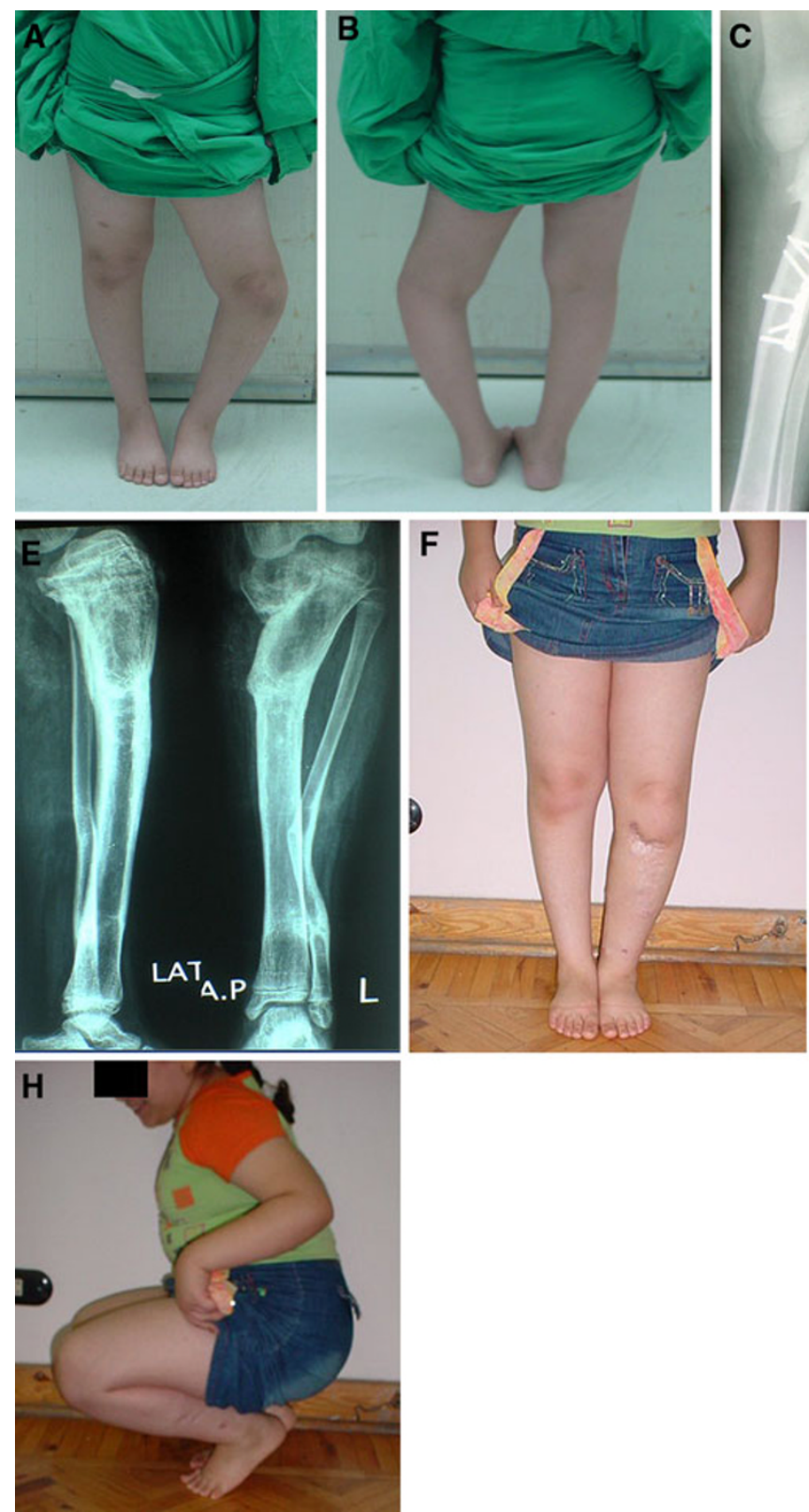

Fig. 6 Clinical photographs and X-rays of case no. 4, a female patient 9 years old with grade VI infantile tibia vara that had a previous corrective osteotomy followed by recurrence of the deformity. a, b Preoperative clinical photographs, c Preoperative X-ray,

\section{Results}

Both osteotomies healed completely in all patients. The mean time in the frame was 23 weeks (ranging from 21 to 28 weeks). The mean preoperative femoral shaft-tibial shaft angle was $36^{\circ}$ of varus (ranging from $26^{\circ}$ to $54^{\circ}$ ), improved to $5^{\circ}$ of varus (ranging from $14^{\circ}$ varus to $4^{\circ}$ valgus). The mean preoperative femoral condyle-tibial shaft angle was $58^{\circ}$ (ranging from $46^{\circ}$ to $66^{\circ}$ ), improved to $84^{\circ}$ (ranging from $77^{\circ}$ to $90^{\circ}$ ). The mean preoperative
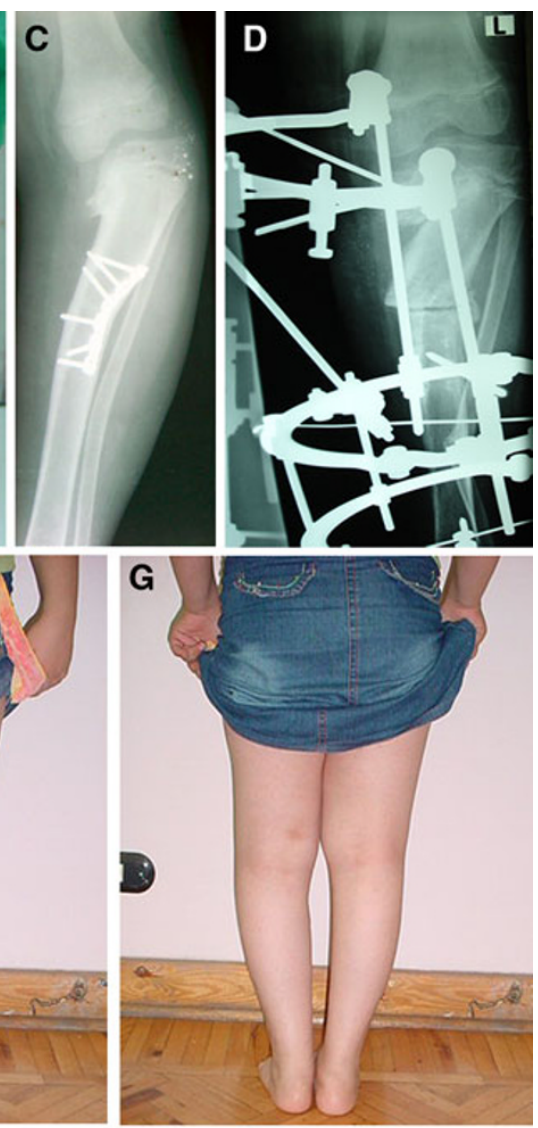

d X-ray in the frame, e X-rays obtained 4 years following frame removal, f-h Final clinical photographs showing correction of the deformity and a full range of knee motion

angle of depressed medial tibial plateau was $63^{\circ}$ (ranging from $45^{\circ}$ to $85^{\circ}$ ), improved to $8^{\circ}$ (ranging from $15^{\circ}$ to $0^{\circ}$ ).

The preoperative range of movement of the knee joint was maintained within $5^{\circ}$ in all patients. All patients were maintaining full extension of the knee at the final follow-up. All patients noticed a significant improvement in the gait pattern (Fig. 6).

Mild to moderate pin tract infection was encountered in 3 patients (4 limbs) but improved with oral antibiotics and local pin site care. Most of the pin tract infection was 
Table 1 Details of the study group

\begin{tabular}{|c|c|c|c|c|c|c|c|c|}
\hline \multirow[t]{2}{*}{ Case no. } & \multirow[t]{2}{*}{ Race/sex } & \multirow[t]{2}{*}{ Grade* } & \multicolumn{2}{|c|}{ Femoral shaft-tibial shaft angle } & \multicolumn{2}{|c|}{ Femoral condyle-tibial shaft angle } & \multicolumn{2}{|c|}{ Angle of depression of medial tibial plateau } \\
\hline & & & Pre & Final & Pre & Final & Pre & Final \\
\hline 1 & $\mathrm{~W} / \mathrm{M}$ & VI & -26 & 5 & 66 & 85 & 45 & 0 \\
\hline 2 & $\mathrm{~B} / \mathrm{F}$ & V & -54 & -14 & 46 & 77 & 85 & 15 \\
\hline $3 \mathrm{~L}$ & $\mathrm{~B} / \mathrm{M}$ & VI & -42 & 0 & 52 & 90 & 64 & 10 \\
\hline $3 R$ & & VI & -39 & -4 & 55 & 88 & 70 & 5 \\
\hline 4 & $\mathrm{~W} / \mathrm{F}$ & VI & -30 & -5 & 63 & 82 & 50 & 5 \\
\hline $5 \mathrm{~L}$ & $\mathrm{~B} / \mathrm{M}$ & V & -38 & -6 & 57 & 84 & 70 & 8 \\
\hline $5 \mathrm{R}$ & & V & -36 & -8 & 57 & 82 & 75 & 8 \\
\hline $6 \mathrm{~L}$ & W/M & V & -30 & 5 & 65 & 88 & 56 & 5 \\
\hline $6 \mathrm{R}$ & & V & -28 & 2 & 64 & 90 & 55 & 5 \\
\hline 7 & W/M & VI & -35 & -11 & 58 & 79 & 60 & 11 \\
\hline $8 \mathrm{~L}$ & $\mathrm{~B} / \mathrm{F}$ & VI & -40 & -8 & 55 & 82 & 65 & 12 \\
\hline $8 \mathrm{R}$ & & VI & -39 & -10 & 55 & 80 & 65 & 14 \\
\hline
\end{tabular}

$L$ left, $R$ right, $W$ white, $B$ black, $M$ male, $F$ female, - varus

* According to the Langenskiold classification

related to the proximal half pins. There was, however, no need for changing any of the half pins or wires in any of the frames applied. No cases of septic arthritis of the knee were encountered. At the final follow-up, there was no evidence of recurrence of the deformity clinically or radiologically in any of the patients.

A summary of the study group details is shown in Table 1 .

\section{Discussion}

The current treatment of choice for neglected infantile tibia vara is gradual correction, which requires less invasive surgery, allows progressive and adjustable correction, permits bone lengthening if needed and achieves a more accurate correction [10, 12-16, 22, 23].

The elevation of the depressed medial tibial plateau allows restoration of the joint architecture, corrects part of the overall deformity [17] and improves any medial ligamentous laxity [24].

The authors have been using the double elevation osteotomy together with the Ilizarov frame to manage cases of neglected infantile tibia vara of stages V and VI [21] according to the Langenskiold classification [2]. Although no serious complications occurred during the previously published series [21], yet the curved osteotomy was always technically demanding and a potential complication was the propagation of the osteotomy to an intra-articular fracture. Such intra-operative complication creates an unsalvageable situation and demands instant internal fixation. Performing this osteotomy had to be done with great care and the fact that this step of the operation is technically demanding potentially reduces the reproducibility of this technique.

Due to the small number of patients that fit the inclusion criteria for this study, the reproducibility of the technique could not be tested. However, compared to hammering on the curved osteotome, which could cause an intra-articular fracture, the pulling force applied to the Gigli saw cannot cause this potentially disastrous complication.

We believe that this modification of the surgical technique of the double elevation osteotomy will motivate more surgeons to adopt this technique for tackling these challenging cases. The potential advantage of this modification includes reduced intra-operative time, less blood loss and being more reproducible and safe.

Acknowledgments None of the authors received financial support in relation to this study. The board of the Orthopedic Department at Ain Shams University has approved this study from the scientific and ethical point of view. This study meets the ethical standards and comply with the national as well as the local standards set within the department.

Open Access This article is distributed under the terms of the Creative Commons Attribution Noncommercial License which permits any noncommercial use, distribution, and reproduction in any medium, provided the original author(s) and source are credited.

\section{References}

1. Blount WP (1966) Tibia vara, osteochondrosis deformans tibiae. Curr Pract Orthop Surg 3:141-156

2. Langenskioeld A, Riska EB (1964) Tibia Vara (Osteochondrosis Deformans Tibiae): a survey of seventy-one cases. J Bone Joint Surg Am 46:1405-1420 
3. Langenskiold A (1981) Tibia vara: osteochondrosis deformans tibiae. Blount's disease. Clin Orthop Relat Res 158:77-82

4. Sibert JR, Bray PT (1977) Probable dominant inheritance in Blount's disease. Clin Genet 11:394-396

5. Bell SN, Campbell PE, Cole WG, Menelaus MB (1985) Tibia vara caused by focal fibrocartilaginous dysplasia. Three case reports. J Bone Joint Surg Br 67:780-784

6. Beskin JL, Burke SW, Johnston CE, Roberts JM (1986) Clinical basis for a mechanical etiology in adolescent Blount's disease. Orthopedics 9:365-370

7. Cook SD, Lavernia CJ, Burke SW, Skinner HB, Haddad RJ Jr (1983) A biomechanical analysis of the etiology of tibia vara. J Pediatr Orthop 3:449-454

8. Dietz WH Jr, Gross WL, Kirkpatrick JA Jr (1982) Blount disease (tibia vara): another skeletal disorder associated with childhood obesity. J Pediatr 101:735-737

9. Langenskiold A (1989) Tibia vara. A critical review. Clin Orthop Relat Res 246:195-207

10. Alekberov C, Shevtsov VI, Karatosun V, Gunal I, Alici E (2003) Treatment of tibia vara by the Ilizarov method. Clin Orthop Relat Res 409:199-208

11. De Pablos J, Azcarate J, Barrios C (1995) Progressive openingwedge osteotomy for angular long-bone deformities in adolescents. J Bone Joint Surg Br 77:387-391

12. Feldman DS, Madan SS, Koval KJ, van Bosse HJ, Bazzi J, Lehman WB (2003) Correction of tibia vara with six-axis deformity analysis and the Taylor spatial frame. J Pediatr Orthop 23:387-391

13. Greene WB (1993) Infantile tibia vara. J Bone Joint Surg Am 75:130-143

14. Laville JM, Chau E, Willemen L, Kohler R, Garin C (1999) Blount's disease: classification and treatment. J Pediatr Orthop B $8: 19-25$
15. Rozbruch SR, Blyakher A, Haas SB, Hotchkiss R (2003) Correction of large bilateral tibia vara with the Ilizarov method. J Knee Surg 16:34-37

16. Johnston CE (1990) Infantile tibia vara. Clin Orthop Relat Res 255:13-23

17. Gregosiewicz A, Wosko I, Kandzierski G, Drabik Z (1989) Double-elevating osteotomy of tibiae in the treatment of severe cases of Blount's disease. J Pediatr Orthop 9:178-181

18. Jones S, Hosalkar HS, Hill RA, Hartley J (2003) Relapsed infantile Blount's disease treated by hemiplateau elevation using the Ilizarov frame. J Bone Joint Surg Br 85:565-571

19. Schoenecker PL, Johnston R, Rich MM, Capelli AM (1992) Elevation of the medial plateau of the tibia in the treatment of Blount disease. J Bone Joint Surg Am 74:351-358

20. Siffert RS (1982) Intraepiphyseal osteotomy for progressive tibia vara: case report and rationale of management. J Pediatr Orthop 2:81-85

21. Hefny H, Shalaby H, El Kawy S, Thakeb M, Elmoatasem E (2006) A new double elevating osteotomy in management of severe neglected infantile tibia vara using the Ilizarov technique. J Pediatr Orthop 26:233-237

22. De Pablos J, Alfaro J, Barrios C (1997) Treatment of adolescent Blount disease by asymmetric physeal distraction. J Pediatr Orthop 17:54-58

23. Feldman DS, Madan SS, Ruchelsman DE, Sala DA, Lehman WB (2006) Accuracy of correction of tibia vara: acute versus gradual correction. J Pediatr Orthop 26:794-798

24. Tavares JO, Molinero K (2006) Elevation of medial tibial condyle for severe tibia vara. J Pediatr Orthop B 15:362-369 